Temporary Modifications To

Access Limits Under The Large

Natural Disaster Window Of The

Rapid Credit Facility And Of The

Rapid Financing Instrument 


\section{INTERNATIONAL MONETARY FUND}

\section{IMF POLICY PAPER}

\section{TEMPORARY MODIFICATIONS TO ACCESS LIMITS}

UNDER THE LARGE NATURAL DISASTER WINDOW OF THE RAPID CREDIT FACILITY AND OF THE RAPID FINANCING INSTRUMENT

IMF staff regularly produces papers proposing new IMF policies, exploring options for reform, or reviewing existing IMF policies and operations. The following documents have been released and are included in this package:

\section{- A Press Release.}

- The Staff Report, prepared by IMF staff and completed on June 8, 2021 for the Executive Board's consideration on June 21, 2021.

The IMF's transparency policy allows for the deletion of market-sensitive information and premature disclosure of the authorities' policy intentions in published staff reports and other documents.

Electronic copies of IMF Policy Papers are available to the public from http://www.imf.org/external/pp/ppindex.aspx

\section{International Monetary Fund Washington, D.C.}




\title{
IMF Executive Board Approves Temporary Increases to Access Limits Under the Large Natural Disaster Window of the Rapid Credit Facility and of the Rapid Financing Instrument
}

\author{
FOR IMMEDIATE RELEASE
}

\begin{abstract}
Washington, DC - June 21, 2021: On June 21, the Executive Board of the International Monetary Fund (IMF) approved temporary modifications to access limits under the large natural disaster (LND) windows of the Rapid Credit Facility (RCF) and of the Rapid Financing

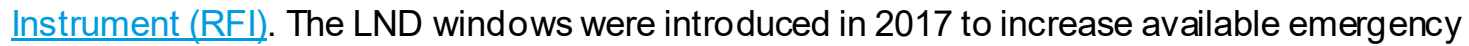
financing for member countries experiencing urgent balance of payments needs arising from large natural disasters where economic damage is equivalent to or exceeds 20 percent of a country's GDP.
\end{abstract}

The temporary modifications increased the annual and cumulative access limits under the LND windows of the RCF and RFI by 50 percent of quota. This is in line with other recent decisions to temporarily modify access limits under the RCF and RFI to increase available emergency financing for countries responding to the COVID-19 pandemic. These modifications under the LND windows enhance the IMF's agility and flexibility to respond to large natural disasters.

The modifications to access limits under the LND windows of the RCF and RFI will be in effect through end-2021. This is in line with the lapse of the increases in annual and cumulative access limits that apply to the RCF and RFI, introduced in April 2020 and extended in October $\underline{2020}$ and March 2021. 


\section{INTERNATIONAL MONETARY FUND}

June 8, 2021

TEMPORARY MODIFICATIONS TO ACCESS LIMITS UNDER

THE LARGE NATURAL DISASTER WINDOW OF THE RAPID

CREDIT FACILITY AND OF THE RAPID FINANCING INSTRUMENT

\section{EXECUTIVE SUMMARY}

To help support members faced with the COVID-19 pandemic, the Fund temporarily increased certain access limits to its emergency financing (EF) instruments, i.e., Rapid Credit Facility (RCF) and Rapid Financing Instrument (RFI). While this expanded support has been critical to help countries manage the pandemic, the increase in access limits was not applied to the Large Natural Disasters (LND) windows within the EF toolkit, reducing the flexibility to respond to such LNDs.

This paper proposes to temporarily increase by 50 percent of quota the annual access limit (AAL) and cumulative access limit (CAL) under the LND windows of the RCF and RFI. The changes to the "LND windows" would be in effect through end-December 2021, in line with the other temporary changes of access limits under EF instruments. The case for further extensions to all the temporarily increased EF AALs and CALs will be examined after the 2021 Annual Meetings. 
Approved By Yan Liu, Christian Mumssen, and Uma Ramakrishnan
Prepared by the Strategy, Policy and Review Department, Finance Department, and Legal Department. The team was under guidance of Charleen Gust, Gabriela Rosenberg, and Chad Steinberg, and comprised Giulio Lisi, Wes McGrew, Toomas Orav, Kiichi Tokuoka (SPR), Beata Jajko, Linda Kaltani, Niklas Johan Westelius (FIN), Kyung Kwak, and David McDonnell (LEG). Catherine Chiew Ming Koh (SPR) provided research assistance and Merceditas San Pedro-Pribram and Phyo Zin (SPR) provided administrative support.

\section{CONTENTS}

INTRODUCTION

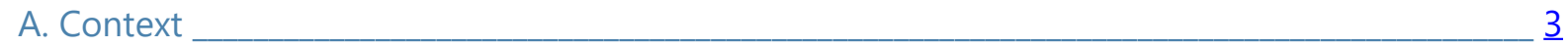

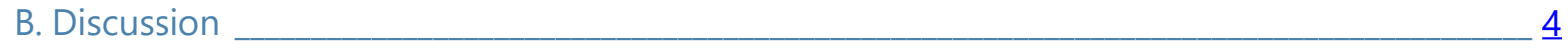

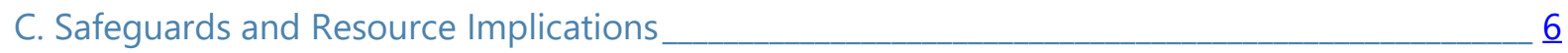

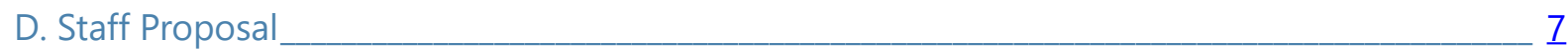

\section{FIGURES}

1. Number of Countries with EF Cumulative Access at or Above $100 \%$ of Quota $\underline{5}$

2. Number of countries with EF Access at or Above $50 \%$ of Quota Over Previous 12 Months ___ $\underline{5}$

TABLE

1. Countries with Approved Financial Support through the Emergency Financing Instruments __ $\underline{8}$

\section{ANNEXES}

I. Instrument to Establish the Poverty Reduction and Growth Trust-Redlined Version of Section II, paragraph 2(b)

II. Rapid Financing Instrument—Redlined Version of Paragraph 5

\section{Appendix}




\section{INTRODUCTION}

\section{The Fund has provided significant support to members faced with the COVID-19} pandemic through its emergency financing (EF) instruments. The Fund temporarily increased certain access limits in the GRA and PRGT, which have been extended through end-2021. While this support has been critical to help countries manage the shock from the pandemic, it is also important to ensure that the Fund has sufficient flexibility to provide non-pandemic-related support for urgent balance of payments (BOP) needs arising from severe natural disasters. With that aim in mind, this paper proposes to temporarily increase by 50 percent of quota the annual access limit $(A A L)$ and cumulative access limit (CAL) under the "LND window" of the Rapid Credit Facility (RCF) and Rapid Financing Instrument (RFI) through December 31, 2021 to restore the access limits across the RCF/RFI windows at a level relative to their pre-pandemic period and ensure that the Fund's emergency financing to support member through the COVID-19 pandemic is truly additional.

\section{A. Context}

\section{The RFI and RCF are valuable elements of the disaster risk financing toolkit for Fund} members. Generally, members qualify for EF under the RCF and/or RFI when certain conditions are met, in particular (i) they are facing an urgent BOP need, and (ii) either the urgent BOP need is expected to be resolved within one year, with no major policy adjustments being necessary, or the member lacks capacity to implement a Upper Credit Tranche (UCT)-quality program due to its limited implementation capacity or due to the urgent nature of the BOP need. BOP needs may be caused by different factors including exogenous shocks, commodity price shocks, natural disasters, and emergence from conflict, as well as other factors such as domestic instability, emergencies, and fragility.

- RCF financing. Concessional assistance under the RCF is available to all PRGT-eligible member countries that meet the qualification requirements. Access to the RCF is subject to both 'global' AALs and CALs under the PRGT and RCF-specific sub-ceilings. Prior to the pandemic, these subceilings were set at 50 percent of quota annually and 100 percent of quota cumulatively, net of scheduled repayments, ${ }^{1}$ while higher access under these RCF sub-ceilings is provided for under the "LND window" when damage from a natural disaster is assessed to be equivalent to or

\footnotetext{
1 These ceilings applied to the "regular widow" and the "exogenous shock window". For RCF access for urgent BOP needs that are caused by neither exogenous shocks nor large natural disasters, RCF drawings were limited to two per year and disbursements are subject to a norm of 25 percent of quota and a per-disbursement limit of 25 percent of quota. All references to EF windows are not special facilities under the RCF and RFI and are used to refer to the circumstances under which relevant sub-ceilings apply.
} 
exceed 20 percent of the member's GDP., ${ }^{2,3}$ In such a case, RCF annual and cumulative limits are 80 percent of quota and 133.33 percent of quota, net of scheduled repayments.

- RFI financing. Assistance under the RFI is available to all member countries meeting the qualification requirements. Pre-pandemic access was subject to an AAL and a CAL of 50 and 100 percent of quota, respectively. Like the RCF, these access limits are increased under the LND window (AAL and CAL of 80 and 133.33 percent of quota, respectively).

\section{In response to the COVID-19 pandemic, access limits under the RFI and the} "exogenous shock window" of the RCF were temporarily raised. The AAL and the CAL under the $\mathrm{RFI}$ and under the "exogenous shocks window" of the RCF were increased by 50 percentage points on a temporary basis to 100 and 150 percent of quota (net of scheduled repurchases and repayments), respectively on April 6, 2020. The temporary increases in access limits have since been twice extended and are currently in place through December 31, 2021. These temporary increases have helped facilitate EF in response to the pandemic in 73 countries to date, of which 45 countries received 100 percent of quota (see Table 1$)^{4}$

\section{The temporary changes approved during the pandemic did not apply to all RCF/RFI} access limits, which has implications for countries that may experience future urgent balance of payments needs. In particular, the augmented access limits under the "LND windows" of the RCF and RFI were not raised at the time and remained at 80 and 133.33 percent of quota (annually and cumulatively), below the increased temporary limits. This implies that countries that have used EF for pandemic-related needs and subsequently experience a qualifying LND may not have additional room to meet the LND-related needs, which is at odds with the original intent of the LND access policy.

\section{B. Discussion}

\section{Since the temporary increases in cumulative access limits were not reflected across all RCF/RFI windows, they may unduly constrain some countries in accessing EF if faced by}

\footnotetext{
${ }^{2}$ When the LND window was established in 2017, it aimed to provide higher access than the limits applicable to all other RCF/RFIs in unique circumstances (i.e. urgent balance of payments needs resulting from a natural disaster that occasions damage equivalent to or to exceed 20 percent of the member's GDP from a natural disaster). The disaster damage threshold was designed to safeguard Fund resources. The "LND window" has not been accessed to date. For further background on the "LND windows," please see May 2017 policy paper on Large Natural Disasters-Enhancing the Financial Safety Net for Developing Countries.
}

3 Prior to the 2019 LIC facilities review, the regular RCF sub-ceilings could be exceeded under both the "exogenous shocks window" and the "LND window." However, with the reforms approved in the 2019 facilities review, the regular RCF access limit was raised to be aligned with the one applicable under the "exogenous shocks window." Augmented access continued to apply to the "LND window."

${ }^{4}$ On May 22, 2021, two approved RFI purchases (Guatemala and Paraguay) were cancelled, both having been undrawn for an extended period. 
qualifying shocks. ${ }^{5}$ The number of countries with EF credit outstanding rose from 22 at end-2019 to 73 at end-2020. Based on outstanding EF exposure (as of end-April 2021), about two-thirds of this group will have cumulative EF credit outstanding of 100 percent of quota or higher (19 GRAonly countries and 27 PRGT-eligible countries). Space for new EF access will recover over time as repayments are made, but EF exposure will remain at or above 100 percent of quota for 19 countries through 2023 - leaving only 33.3 percent of quota access under the LND CAL (Figure 1). ${ }^{6}$ Six of these countries (Dominica, Madagascar, Mozambique, Nepal, Samoa, and St. Vincent and the Grenadines) would be even more constrained by CAL given that they accessed EF support for the pandemic of 100 percent of quota and had EF credit outstanding that predates the pandemic. A number of these countries have experienced multiple natural disasters since $2000{ }^{7}$

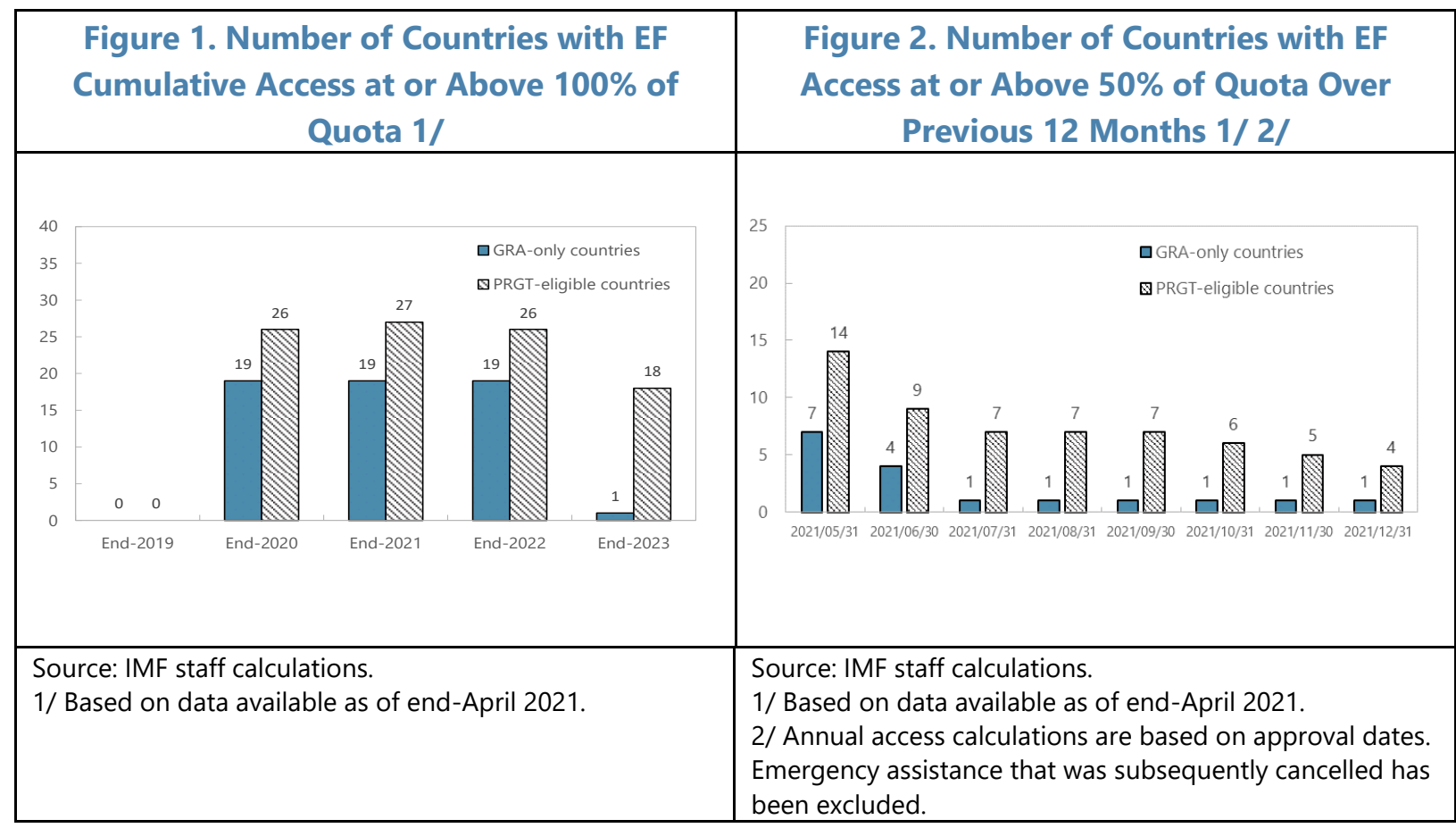

\section{While initially large, the number of countries constrained by EF annual access limits} has declined rapidly. Given the clustering of EF support in response to the pandemic in April-May 2020, four GRA-only countries and nine PRGT-eligible countries are projected to have their past 12month EF access at or above 50 percent of quota at end-June 2021 (Figure 2).

\footnotetext{
${ }^{5}$ Outstanding disbursements from all RCF (and RFI) windows are included in calculating cumulative access (SM/19/100, footnote 46). Similarly, for the calculation of annual access, outstanding disbursements from all RCF (and $\mathrm{RFI}$ ) windows are included in calculating the RCF/RFI sub-ceiling annual access limits. In each case, calculations are based on Board approval dates and approved amounts of EF assistance under all "windows."

${ }^{6}$ While the RFI should be repaid within $31 / 4$ to 5 years, RCF financing involves a grace period of $51 / 2$ years and a final maturity of 10 years, so EF access would recover more slowly for PRGT-eligible countries.

${ }^{7}$ See Tables 2 and 3 in the May 2017 policy paper on Large Natural Disasters_Enhancing the Financial Safety Net for Developing Countries.
} 


\section{There is a strong case for temporarily changing the AAL and CAL EF access limits for} RCF/RFI LND to allow for augmented access as was the case in the pre-pandemic period. The original intent of the higher limits under the "LND windows" has been to allow members access above regular RCF/RFI access limits, provided that the member has an urgent BOP need and the natural disaster resulted in damage assessed equivalent to or to exceed 20 percent of the members GDP, which is currently not the case. ${ }^{8}$ Increasing these limits by 50 percent of quota would be consistent with the intent of the temporary access limit increases in April 2020 - that the increase in EF limits provided by the Fund for the pandemic response should be truly additional. ${ }^{9}$

\section{Safeguards and Resource Implications}

\section{Risks to safeguards of the Fund's resources because of the higher cumulative limit under the "LND windows" of the RCF and RFI would be manageable. The new safeguards} introduced in March 2021 to support the extensions of the higher GRA and PRGT access limits are also applicable to the current proposals, and additional safeguards are not needed. These include the safeguards for early consultations with the Board via informal Board briefings where access levels to Fund resources are elevated. Given the risk of "facility arbitrage" where countries request financial assistance through EF instruments in situations where an arrangement with a UCT-quality program would be more appropriate and feasible, the rigorous application of qualification criteria was emphasized and it was agreed that staff reports accompanying any EF request explicitly discuss how the qualification criteria are met. Finally, the disaster damage threshold under the LND window of the RFI and RCF remains appropriate, and complements these safeguards by ensuring that the higher access available via the "LND window" would be only available for countries facing large, urgent balance of payments need arising from a natural disaster meeting the specified threshold.

\section{The proposed changes would have a modest impact on GRA resources, and risks to}

PRGT sustainability would be small. Given that the proposed increases in AALs and CALs are temporary and there is a low likelihood of qualifying events occurring, it is expected that the resource implications on both the GRA and PRGT would be minimal. ${ }^{10}$ Any mobilization of necessary resources for the PRGT linked to these proposed limits increases will be part of a broader concessional financing package that would be developed alongside wider PRGT reforms.

\footnotetext{
${ }^{8}$ Natural disasters include geophysical events (earthquakes, volcanic activity), meteorological events (extreme temperatures, storms), hydrological events (floods, wave action), climatological events (drought, wildfire), and biological events (epidemics and insect infestation) (SM/17/76, footnote 1). The COVID-19 pandemic is such a natural disaster, but the high damage threshold generally rules out access under the "LND window."

${ }^{9}$ Instead of increasing CAL, in July 2020 the Board discussed the option to "carve out" access to the emergency financing instruments from the cumulative limit, but this was not pursued. The July 2020 paper on temporary modifications to the Fund's annual access limits (see here) reviewed the limitations of this option.

10 One country is currently expected to request RCF assistance under the "LND window."
} 


\section{Staff Proposal}

\section{Staff proposes to temporarily increase by $\mathbf{5 0}$ percentage points of quota the AAL and} CAL under the "LND windows" through December 31, 2021. This is in line with the annual and cumulative access limits increases (50 percentage points) approved by the Board in April 2020 under the RFI and under the "exogenous shocks window" of the RCF.

- Raise AAL under the "LND window" of the RCF and RFI from 80 to 130 percent of quota, and CAL under the "LND window" of the RCF and RFI from 133.33 to 183.33 percent of quota (net of scheduled repurchases and net of scheduled repayments). This would increase by roughly 40 percent the number of countries with available borrowing space of 80 percent of quota in the event of a qualifying large natural disaster (i.e. the pre-pandemic annual access limit). Small and micro developing states that are vulnerable to such shocks would benefit, with at least 80 percent of quota available to all countries under AALs and creating that amount of space for 10 potentially constrained countries under CALs. ${ }^{11,12}$

- As previously agreed by the Board in March 2021, the case for further extension to the EF AALs and CALs will be examined after the 2021 Annual Meetings, by which time the pandemic-linked uncertainty regarding the economic outlook may have abated..$^{13}$

\section{The paper sets forth two proposed decisions for adoption by the Executive Board.}

Decision I would implement the proposed amendments regarding the RCF to the Poverty Reduction and Growth Trust (PRGT) Instrument. Decision II would implement the proposed amendments to the RFI decision. Annexes I and II set forth redlined texts that show revisions against the current PRGT Instrument and RFI Decision incorporating the proposed modifications.

\footnotetext{
11 The classification of small and micro developing states is based on the 2017 staff guidance note on the Fund's engagement with small developing states (see here). Under higher limits, three such countries would remain constrained (Dominica, Samoa, St. Vincent and the Grenadines) with available access under the LND ranging from 37 to 70 percent of quota due to pre-pandemic EF credit outstanding.

12 Some PRGT-eligible countries may be constrained by overall PRGT access limits and some GRA-only countries could be constrained by the overall GRA access limits which trigger the exceptional access (EA) policy.

13 Should the increases in annual and cumulative limits cease to be effective, the outstanding credit resulting from the RCF and RFI disbursements or purchases through December 31, 2021 may result in some countries exceeding the RCF/RFI annual and cumulative limits; such credit will count towards the applicable PRGT and GRA access limits (see FN 10 of SM/20/82, "Enhancing the Emergency Financing Toolkit - Responding to the COVID-19 Pandemic").
} 


\section{Proposed Decisions}

The following decisions, which may be adopted by a majority of the votes cast, are proposed for adoption by the Executive Board:

\section{Decision I: Amendment to the PRGT Instrument}

The following sentence shall be added at the end of section II, paragraph 2(b)(ii) of the Instrument to Establish the Poverty Reduction and Growth Trust ("PRGT Instrument"), Annex to Decision No. 8759-(87/176) ESAF, adopted December 18, 1987, as amended:

"For the period from [date of Board approval of this decision] to December 31, 2021, these annual and cumulative access limits shall be 130 percent of quota and 183.33 percent of quota, net of scheduled repayments, respectively;"

\section{Decision II: Amendment to the RFI Decision}

The following sentence shall be added at the end of paragraph 5 of the Decision establishing the Rapid Financing Instrument (RFI), Decision No. 15015-(11/112), November 21, 2011, as amended:

"For the period from [date of Board approval of this decision] to December 31, 2021, these annual and cumulative access limits shall be 130 percent of quota and 183.33 percent of quota, net of scheduled repurchases, respectively." 


\section{Annex I. Instrument to Establish the Poverty Reduction and Growth Trust-Redlined Version of Section II, paragraph 2(b)}

Introductory Section

To help fulfill its purposes, the International Monetary Fund (hereinafter called the "Fund") has adopted this Instrument establishing the Poverty Reduction and Growth Trust (hereinafter called the "Trust"), which shall be administered by the Fund as Trustee (hereinafter called the "Trustee"). The Trust shall be governed by and administered in accordance with the provisions of this instrument.

Section II. Trust Loans

$* * * * * * *$

Paragraph 2. Amount of Assistance

(b) Subject to the provisions in subparagraphs (i) to (iv) below, the access of each eligible member under the RCF shall be subject to an annual limit of 50 percent of quota, and a cumulative limit of 100 percent of quota, net of scheduled repayments, including where the assistance is requested to address an urgent balance of payments need resulting primarily from a sudden and exogenous shock and the member's existing and prospective policies are sufficiently strong to address the exogenous shock:

(i) each disbursement shall not exceed 25 percent of quota except where the member requests assistance under the RCF to address an urgent balance of payments need resulting primarily from a sudden and exogenous shock (including a large natural disaster under (ii) below);

CInternational Monetary Fund. Not for Redistribution 
(ii) the annual and cumulative access limits under the RCF shall be 80 percent of quota and 133.33 percent of quota, net of scheduled repayments, respectively, where (a) the member requests assistance under the RCF to address an urgent balance of payments need resulting from a natural disaster that occasions damage assessed to be equivalent to or to exceed 20 percent of the member's gross domestic product (GDP) and (b) the member's existing and prospective policies are sufficiently strong to address the natural disaster shock. For the period from [date of Board approval of this decision] to December 31, 2021, these annual and cumulative access limits shall be 130 percent of quota and 183.33 percent of quota, net of scheduled repayments, respectively;

(iii) for the period from April 6, 2020 to December 31, 2021, a member's request for assistance under the RCF to address an urgent balance of payments need resulting primarily from a sudden and exogenous shock shall be subject to an annual access limit of 100 percent of quota and a cumulative access limit of 150 percent of quota, net of scheduled repayments; and

(iv) outstanding credit by a member under the rapid-access component of the ESF or outstanding purchases from the General Resources Account under emergency post conflict/natural disaster assistance covered by Decision No. 12341-(00/117), shall count towards the annual and cumulative limits applicable to access under the RCF. With effect from July 1, 2015, any purchases from the General Resources Account under the Rapid Financing Instrument shall count towards the annual and cumulative limits applicable to access under the RCF. 


\title{
Annex II. Rapid Financing Instrument-Redlined Version of Paragraph 5
}

\begin{abstract}
$* * * * * * *$
5. Assistance under this Decision shall be made available to members in the form of outright purchases. Access by members to resources under this Decision shall be subject to (a) an annual limit of 50 percent of quota, and (b) a cumulative limit of 100 percent of quota, net of scheduled repurchases, provided that:
\end{abstract}

A. for the period from April 6, 2020 to December 31, 2021, the above annual and cumulative access limits shall be 100 percent of quota and 150 percent of quota, net of scheduled repurchases, respectively; and

B. the annual access limit shall be 80 percent of quota and the cumulative access limit shall be 133.33 percent of quota, net of scheduled repurchases, where (i) the member requests assistance under the RFI to address an urgent balance of payments need resulting from a natural disaster that occasions damage assessed to be equivalent to or to exceed 20 percent of the member's gross domestic product (GDP), and (ii) the member's existing and prospective policies are sufficiently strong to address the natural disaster shock. For the period from [date of Board approval of this decision] to December 31, 2021, these annual and cumulative access limits shall be 130 percent of quota and 183.33 percent of quota, net of scheduled repurchases, respectively. 